\title{
Becoming a Backpacker in China: \\ A grounded theory approach to identity construction of backpackers
}

\begin{abstract}
Backpacking tourism has gained in popularity among Chinese young people since the 1990s. While learning from their western counterparts, Chinese backpackers have also developed their own unique group identification strategies. By focusing on how backpacker identity is socially constructed in the Chinese context, this research explores the meaning and process of becoming a backpacker in China. Grounded theory was adopted, and the structure "image-identitystrategy" emerged to organise the process of becoming a backpacker into three phases. The findings show that Chinese backpackers employ various strategies to continuously negotiate and reconstruct their backpacker identity. It is thereby shown how the process itself of becoming a backpacker is always ongoing.
\end{abstract}

Keywords: backpackers, backpacking, identity, social construction, becoming, grounded theory 


\section{Introduction}

The development of backpacking tourism has been accompanied by a proliferation of research in this field. Backpackers are generally considered by scholars to be a socially constructed community (Adkins \& Grant, 2007; Welk, 2004), in that they form a unique group style and share similar values and behaviours. For most of them backpacking is not only a travel form, but also an expression of identity. The "backpacker" label embodies ideals of independence, freedom, adventure, self-transformation and personal development (Elsrud, 2001; Noy, 2004; O'Reilly, 2005). Therefore, the identity construction of backpackers has been considered an important topic in backpacker studies (S. A. Cohen, 2010; Currie, Campbell-Trant, \& Seaton, 2011; O'Reilly, 2005). However, research on backpacking has generally been Western-oriented, with researchers predominantly focusing on "Western" backpackers (Cohen and Cohen, 2015; Teo and Leong, 2006). As Cohen and Cohen (2015) put it, although sharing some similarities from an etic perspective, the emic interpretation of tourism in emerging regions, like Asia, the Middle East and Latin America, is quite different from the West. Therefore, more emic research from these emerging regions is called for to overcome the Eurocentric bias in tourism studies.

Benefiting from reforms and the "opening-up" policy in China that has occurred since the late 1970s, Chinese people have had much more opportunity to travel than ever before. In the 1990s, backpacking tourism, perceived as an "exotic" style of travel, became popular among Chinese youths (Zhu, 2009). With the economic boom particularly in the last decade, the number of Chinese backpackers, travelling both domestically within China and internationally, has significantly increased. Consequently, backpacking has become an important subculture of contemporary Chinese youths. While imitating Western backpackers to some extent, Chinese backpackers have indeed formed their own culture and unique understanding of "backpacking". To date, however, the cultural meanings of this particular group remain under-researched. Therefore, in order to understand this unique culture of backpacking further, this paper aims to extend our understanding of how Chinese backpackers socially and contextually construct their identities as "backpackers". The study set out to explore: What does it mean in China to be(come) a backpacker? Moreover, by regarding "backpacker" as a social construct and emphasising the processes of meaning-production in backpacker-related social behaviour, the study not only highlights the ongoing re-creation processes of "backpacker" as an identity construct, but also how becoming a backpacker is itself always in process. 


\title{
The "Backpacker" literature
}

\author{
"Backpacking" as a form of tourism
}

Modern backpackers, who were initially called "drifters" by Erik Cohen (1972, 1973), can be traced back to the period following the Second World War in Western Europe. Cohen considered them to be the most individualistic and least institutionalised type of tourists due to their being relatively detached from the tourism establishment. However, although backpacking initially had a strong connection with the notion of "counterculture", especially drug-culture (E. Cohen, 1973), this countercultural image was replaced as the social-political context changed. For instance, the educational function of backpacking was emphasised when Vogt (1976) used "wanderers" to identify this group. Thus, they became endowed with a more positive image compared with "drifters". The following decades saw this group's continuing evolution, with these travellers no longer being considered the hedonists or anarchists that Cohen had earlier referred to (Riley, 1988). Their image had become more neutral, neither "heroes" nor "deviants", but rather simply "long-term budget travellers" (Riley, 1988), which indicates perhaps the most important institutional orders of this group.

From the 1990s onwards, the term "backpacker" has become the commonly accepted term with which to identify this group (G. Chen \& Huang, 2017; O’Regan, 2016; Pearce, 1990). This semantic variation also implies the shift of this group from a de-marketing subculture to a marketing segment (Ateljevic \& Doorne, 2004). With the institutionalisation of backpacking, there also emerges more variants of backpackers, such as "short-term backpackers" (Sørensen, 2003) and "flashpackers" (Hannam \& Diekmann, 2010; Paris, 2012). Both of these two subgroups travel "backpacker-like", while the differences between them and what could be considered "traditional" backpackers are that the former are limited by travel time, and also the latter carry expensive technology and show greater purchasing power during their trips. Thus, Riley's (1988) definition, "long-term budget travellers", can no longer be seen to accurately represent contemporary backpackers. Moreover, it has been argued that the differentiation of backpackers from mainstream tourism has lessened (Larsen, Øgaard, \& Brun, 2011). For example, Spreitzhofer (1998, p. 982) considers backpackers to be "a variant of mass tourism on a low budget level". However, no matter how ambiguous the boundaries between backpackers and mainstream tourists become, the term "backpacker" is still used as an expression of identity (S. A. Cohen, 2010; O’Reilly, 2005).

\section{Construction of identity}

Identity, which is a core concept in social sciences, is essentially about the question of "who am I"? However, the understanding of ourselves unavoidably relies on the identification with others. Nowadays, there are two main theoretical streams addressing the social nature of identity (Hogg, Terry, \& White, 1995; Zhou, 2008): one is derived from symbolic interactionism from a sociological perspective, and the other is social identity theory formulated by European social psychologists. 
From the perspective of symbolic interactionism, the self is a product of social interaction and is reflectively constructed by "taking the role of the other" (Mead, 1934). As individuals usually occupy different roles in society, they may have various role identities which are activated in different situations (Stryker, 1980). Through interactions with others, individuals learn to behave corresponding with the roles they are playing. In this way, the meanings of identities are constructed and acquired.

Social identity theory is developed principally by Henri Tajfel and John Turner (Tajfel, 2010; Tajfel \& Turner, 1979; Turner, 1975). It considers society as comprising social categories (e.g., nationality, gender, and occupation). Individuals can locate themselves in society through the process of self-categorisation, and then derive their identities from social categories they belong to, because the defining characteristics of these categories can be constructed as a component of their self-concepts. Social identity, therefore, is not merely knowledge of belonging to a social category, it is also attached to value and emotion.

Although they come from different perspectives, the discussions of both two theoretical streams are premised on constructionism, and assume that identities are neither natural nor static, but rather are dynamic and contextualised. Identities are constructed by different practices in different social contexts. Therefore, to have a better understanding of identity construction of backpackers, the following section will discuss "backpacker" as identity from the individual perspective.

\section{"Backpacker" as identity}

It has been argued that backpackers are keen to differentiate themselves from "tourists" and to label themselves "backpackers" (O'Reilly, 2005), indicating that this travelling identity is an important source of "meaning-making" for these individuals. Therefore, the ways of travelling become the signs representing value orientation and social differentiation. For backpacking, much previous research has already elaborated on what constitutes its institutional orders, such as it being travel which is independently organised and has a flexible travel schedule, often comprises long-term trips, is low budget, getting off the beaten track, seeking authenticity and adventure, and willing to interact with other people (S. A. Cohen, 2011; Loker-Murphy \& Pearce, 1995; Uriely, Yonay, \& Simchai, 2002). To acquire and maintain the identity of this group, backpackers have to follow at least some of these institutional orders.

In this way, these institutional orders are turned into backpackers' behaviour in order to differentiate themselves from mass tourists. For instance, according to Muzaini (2006), backpackers employ different strategies to "look local", which is not only about seeking "authentic experiences", but is also about distancing themselves from mass tourists and also other, less experienced, backpackers. This point suggests, also, another important motivation for backpackers to follow these norms - to establish in-group identity and reputation. Sørensen (2003) points out that road status is a key issue in backpackers' identity. To obtain a higher road status, manipulating information, such as the deliberate scuffing of equipment and the understating of prices, can be found in the interactions of backpackers. Elsrud's (2001) study also suggests that narratives of risk and adventure are another important strategy for backpackers to achieve a higher position in the hierarchy. Likewise, Tucker (2003) argues that "serendipitous experiences" are used as symbolic capital in order to negotiate a "backpacker", or non-tourist, 
identity. Those who have more symbolic capital will have power to (re)define the institutional orders.

However, because of socio-historical change and "massification" of the group, new backpackers will not always comply with the established institutional orders. Some of them may deviate from the predefined patterns of behaviour. When this deviation is widely accepted, it becomes a new institutional order, and the evolution of the group occurs. This cyclic process of backpacker "becoming" has recently been highlighted by Tomazos (2016). However, as with the majority of backpacker studies, Tomazos' discussion of "backpacking through an ontology of becoming" pays no regard to regional, or national, variation. Since nationality and culture inevitably influence the ways and forms in which backpacker identity construction occurs (Maoz, 2007), it is pertinent to develop in-depth understanding of the processes of backpacker identity construction among different regional groups. Moreover, whilst some exploratory studies have highlighted some differences between Chinese and Western backpackers (Long, 2011; Zhu, 2009), there remains a gap in knowledge in relation to the specific meanings and processes of backpacker identity construction in China.

\section{Chinese backpackers}

While the group of Chinese backpackers has experienced significant growth in the last decade, research in this area has lagged behind. Indeed, no attention was paid to this group until a decade or so ago. In the early stages, the majority of research focused on Western backpacking (Zhu, 2005; Zhu \& Lv, 2007), and international backpackers (Su \& Ma, 2009; Zhang, Wu, \& Li, 2007), in China. Recently, more attention has been paid to Chinese backpacking as a form of domestic travel within China, and especially to motivations and behaviours in relation to this form of travel (G. Chen, Bao, \& Huang, 2014a, 2014b; G. Chen \& Huang, 2017; Luo, Huang, \& Brown, 2015). In China, "backpackers" have been referred to as "donkey friends", a term which first emerged via a Chinese backpacker website known as "The Mill" (Lim, 2008). "Donkey (lǘ)" is homophonic with "travel (lü)" in Mandarin, and the way that backpackers carry haversacks is likened to the way in which donkeys carry loads. It is therefore a term, or nickname, for backpackers which is widely accepted by Chinese backpackers themselves, as well as by Chinese scholars (H. Chen \& Weiler, 2014; Zou, Lin, \& Zheng, 2014).

Along with employing such unique vocabulary, Chinese backpackers also show some different travelling behaviours when compared to known Western backpacker behaviours. Zhu (2009) and Luo et al. (2015) have found that although Chinese backpackers are quite similar to their Western counterparts in terms of demography, they tend to have higher travel expenditure, as well as lower endurance and maturity in backpacking practice. Another notable characteristic of Chinese backpackers is their high dependence on the Internet (Long, 2011; Ong \& du Cros, 2012). As Chinese backpacking emerged in the 1990s, their emergence coincided with the boom in the Chinese Internet industry. The Internet provides Chinese backpackers with a virtual platform on which to gather and communicate, which further stimulates the growth of this group (Long, 2011). Facilitated by the efficient interactions in these virtual communities, and affected by collective values in Chinese culture, preferences for travelling in the company of others is another important trait of Chinese backpackers, some of whom look for travel companions through the Internet before they set out (Miao \& Bao, 2007).

In a similar way to Western backpackers, Chinese backpackers are also faced with the predicament of institutionalisation in that, as backpacking has become integrated into the tourism 
industry, backpacking itself has already become a symbol to be consumed (Z. Chen, 2011). This process of institutionalisation, initially derived from backpackers' practice, continuously (re)constructs the meanings associated with "backpacking", as well as the meaning of "backpacker" as a social identity. Whilst a body of literature on Chinese backpackers has begun to develop an understanding of Chinese backpacker behaviour, little research has focused on the issue of their social (re)construction of backpacker identity. Moreover, most of the research to date on Chinese backpackers is, like much of the existing research on Chinese tourists in general (Wang \& Jin, 2016), based on etic approaches, with only a small sample of research focusing on Chinese tourists' own meaning-making (Lim, 2008; Ong \& du Cros, 2012). There remains a paucity of research which attempts to gain a more emic understanding of how Chinese backpackers negotiate constructions of a backpacker identity, and thereby of what it means to be(come) a backpacker. The present research aims to address this gap.

\section{Study Methods}

To explore Chinese backpacker identity and "becoming", a constructivist grounded theory approach, which lies in the interpretive tradition, was employed in this research. It is important to note from the outset that this research into Chinese backpackers did not set out to compare Chinese and non-Chinese, for example, Western, backpackers. Rather, the research followed grounded theory research design, which encourages emic "understanding" of research participants' meanings, actions and worlds and allows for indeterminacy (Charmaz, 2014). Grounded theory method is generally understood to be a qualitative research strategy to develop theories from data, rather than from preconceived logically deduced hypotheses. Importantly, Glaser and Strauss (1967) suggested researchers use grounded theory strategies flexibly, viewing the grounded theory approach as a set of flexible guidelines rather than rigid rules or requirements.

The basic process of grounded theory includes data collection, coding, memo-writing, theoretical sampling and saturation. In the present research, as suggested by Charmaz (2014), data collection and analysis were undertaken simultaneously, thus aiding the researchers to conduct both theoretical sampling and theory-building. When categories were saturated, data collection was stopped. As it is suggested that "all is data" for grounded theory (Glaser, 2001, p. 145), multiple methods were adopted to collect data. The fieldwork was undertaken between July, 2012 and September, 2014 in the Sichuan and Yunnan Provinces in China, both being top destinations among Chinese backpackers according to Zhu's (2009) content analysis of backpacker online forums. The main target locations within these two provinces were Chengdu, Yading, Dali and Lugu Lake, which represent four different types of destinations (city, mountain, historical town, and lake respectively). The analysis is based mainly upon participant observation and 20 in-depth semi-structured interviews, while 317 completed questionnaires with several open-ended questions, such as regarding impressions of backpackers and mass tourists, were used as complementary material to support the findings. The interviews and surveys generally took place in youth hostels, restaurants, at bus stations, and while trekking. Convenience and snowball sampling were adopted. The formal interviews were audio-recorded. All of the survey and interview respondents could be considered Chinese "domestic" backpackers. Their average age was 24 , with the youngest being 17 and the oldest 45 . There was a slightly higher proportion of males than females. Most of them were well educated (about $90 \%$ were university graduates or held higher degrees). These demographic points correspond with 
the findings of other recent research on Chinese backpackers (G. Chen, et al., 2014a; G. Chen \& Huang, 2017; Yu, 2012).

During the analysis phase of the study, NVivo 8.0 was used to code the data. The coding process consisted of three phases. The first phase included the initial coding, which fragmented and coded the data by sentences, generating 251 initial codes. The second phase was focused coding, which selected the most significant and/or frequent initial codes to categorise the data into a stronger analytic sense. After rigorous comparisons and refinements, six categories emerged; romanticised image, separation, blurred image, social differentiation, reflected image and narrated experience. The last phase aimed to specify possible relationships between these categories and produce a story with coherence. The structure "image-identity-strategy" then emerged from the data to integrate fractured categories together and form the theoretical framework.

\section{Analysis}

\section{Fluid identity}

The analysis of the research data highlights that the identity construction of Chinese backpackers is a continuous, fluid process. To illustrate this process, this section will present the backpacking story of one typical respondent, Xiaohei (female, 22). Xiaohei learned about backpacking through art movies and novels, as well as "real" stories from her friends, which contributed to her belief that backpacking represented the ideal life she seeks and values:

At that time, I thought they were awesome! They are free-spirited and interesting. They enjoy their life, and seek what they like. That is a life I seek too... I guess I didn't really understand what backpacking was at first, but I bought a backpack and even a tent...For me, when I took a backpack and made it part of my daily life, I became a backpacker.

Taking a private affair as the catalyst, she decided to escape from her university life and start a backpacking journey. To make a successful separation, she "manipulated" information in a medical test for depression so that the university could approve her suspension of study for one year. Compared to a gap year for backpacking, depression is a much more acceptable excuse for study deferral. However, she struggled to become what she considered an "eligible backpacker." "I usually compared myself with my expectation and backpackers I met during the journey, to see if I was eligible. It's like if you are a student, you should fulfil your obligations as a student." To fulfil the "obligations" as a backpacker, she followed the backpacking stories she had learned of before. Her first trip was hitchhiking along the Yunnan-Tibet national highway to Tibet. The idea came from the popular TV show Go to Berlin by Thumb and other stories of hitchhiking to Tibet. She "equated backpacking with hitchhiking and some related words", which represented a very different travel activity from mass tourists. However, this practice did not meet her expectations. "It's not as exciting as I heard from the stories." Then she completed other typical "non-tourist" routes in order to reinforce her identity as a backpacker. However, her disappointment grew to expand from herself to the whole group of Chinese backpackers: 
Real backpackers are very different from what I expected... I remember one scene when people were chatting in a hostel garden. The Chinese [backpackers] kept showing off what they had done, how great they were, while the foreigners just shared the joy of their journeys and discussed how to travel in a better way. That is what I expected to be.

As she had more interactions with other Chinese backpackers, this kind of reflection and criticism became stronger, especially toward the end of her travel year. It was also reflective of her own story. For example, she considered the most impressive backpacking story to be one about her friends who trekked through Yarlung Zangbo Grand Canyon. She summarised: "They really took a risk and really encountered an accident", which distinguished them from "most backpackers" who like to exaggerate their risks. Importantly, though, she did not regard those backpackers as "fake." Rather, she believed that with the "massification" of backpackers, they are what the real Chinese backpackers look like. Finally, after she returned to her daily life, her backpacker associations and identity became reconfigured:

In the end, I find that most backpackers are very boring... They are not the backpackers I'd imagined before, and I don't want to be a member of them... The reason they backpack is not to enjoy beauty, but to show off how unique they are... How can they seek a sense of status in this way? For me, the definition of a sense of status has been re-shaped now... Because I know it is easy to do [backpacking]... The uniqueness of backpackers has dissolved. I'd like to adopt other forms of travelling... I was a backpacker during my deferral year, but after that, I am not any more.

Based on this example of Xiaohei, together with the other interview, observation and survey materials, the analysis organised the process of be(com)ing a Chinese backpacker into three phases: (1) Phase I - Transformation of identity; (2) Phase II - (Re)inforcement of identity; and (3) Phase III - (Re)construction of identity. Importantly, although highly related to backpackers' actual travel experiences, these identity-construction phases did not necessarily correspond with the phases of before, during and after the journey. The three phases of be(com)ing a Chinese backpacker are now outlined.

\section{Phase I - Transformation of identity}

\section{Romanticised image}

Image construction is a way for individuals to make sense of the world, and its process needs to be discussed in a larger social and cultural context. As such, images and perceptions of backpackers are largely shaped in China by books, movies, TVs, newspapers and other media, including social media. More specifically, as an "exotic" concept, backpacking tourism in China is primarily influenced by Western representations of backpacking. The characters in Jack Kerouac's representative work On the Road are the most frequently mentioned prototypes of foreign backpackers for Chinese backpackers, with many Chinese backpackers treating them as their idols. The phrase "on the road" itself has become a very persuasive slogan for Chinese 
youths to embark on their backpacking journeys. The particular way the book characters travel also impresses Chinese backpackers, so that, for example, hitchhiking is considered to be a more "real" way of backpacking than taking local buses or trains, as with the case of Xiaohei.

Meanwhile, contemporary travel literature, movies and TV programs in China shape a clear image of backpackers for Chinese. In recent years, travel literature on backpacking has become a bestseller category in the Chinese book market. This has also produced some backpacker "stars", such as Gu Yue and Peng Xiao, whose works Go to Berlin by Thumb, Backpacking for Ten Years, and A Belated Gap Year have become introductory reading material for Chinese young backpackers. The images of backpackers in these works are usually very similar: young men or women who cannot bear their monotonous, routine life quit their stable job and set out on a "hard but romantic" journey (Z. Chen, 2011). These local and contemporary images arouse enthusiasm among Chinese youths to imitate this process of becoming "a backpacker". In these images, Kerouac-like or drifter-like countercultural characteristics are replaced by the narrative of "youth" and "dream". Compared to the Western "drifters" earlier described by Cohen (1973), the so-called rebellion of Chinese backpackers to daily life is more bourgeois, or, in their own words, "xiaoqingxin", which refers to young people who avoid getting involved in socio-political issues but instead seek an aesthetic and romantic life.

Other travellers also may develop their perceptions of backpackers directly during their journeys. The following excerpts from a respondent Yiyi (female, 24) typify such encounters:

Not until I met these backpackers did I realise that travel could be like this!...At that time, I just thought they were so cool, so tough! These guys [backpackers] invited me to go with them to Tibet. I was scared, because I had seen how tough it was to backpack in the mountain areas, especially in the blazing sun. So I said "no, no, I can't make it."

The image of backpackers tends to be romanticised, endowing them with many virtues, such as "freedom", "courage" and "heroism", and the backpackers' long trips also become "cool", "fun" and "amazing". This positive image consequently induces some individuals to want to change from being "non-backpackers" to "potential backpackers". This stage of the process of becoming a backpacker involves strategies of "separation".

\section{Separation}

The identity transformation from "potential backpackers" to "backpackers" does not happen at that very moment when they head off "on the road". This transformation lasts a long period and starts even before they set out. To become a backpacker, one needs a strong belief and enough courage to face various constraints or challenges: "To speak romantically, the most difficult part of the journey is the first step" (Yu, male, 23). During this period, the backpackers need to make an effort to cut the ties binding them to normal daily life, or in other words, to make a "separation".

Students represent a large portion of these young backpackers, and the biggest constraint of their journey is lack of money. As backpacking is often not supported by the family, students without income have to prepare for a long time to raise enough money to travel, often by doing part-time work. Frequently, they also work along the way in order to maximise their travel period. Many youth hostels in China recruit volunteers in return for food and accommodation. 
This has become increasingly popular in recent years, with the development of virtual communities for information exchange about where such work is available.

Another constraint is the time needed away from work and career. With the fierce economic and social competition in contemporary China, the age of 20-30 is considered to be the key age to lay the foundation of one's career. Whilst some students go backpacking during their summer holidays, those who have jobs or who want to expand their travel period have to quit their job, or suspend their study, to take a "gap year". Suspending "normal life" to be a backpacker is generally not in line with the expectations of society, and nor with the expectations of family for many individuals, and is viewed as "a waste of time":

I have some friends who are backpackers. But at that time I was a workaholic, so I thought this was a waste of time. It's not worth to spend such a long time doing this [backpacking]. So I held a negative view on it. (Qin, male, 23)

This suspension of normal life is considered to be running out on responsibilities and breaking the traditional Chinese life-course: completing education - working hard - saving money - getting married - buying a house. Therefore, one may face the risk of losing career opportunities, future lack of income, and even "bachelordom" (for men) when one makes the decision to be a backpacker.

Female Chinese backpackers confront considerably more social pressure than men. Traditional Chinese culture asserts the idea that a noble woman had better stay at home and not do anything to "stand out". Although the power of these traditional values has lessened in contemporary Chinese society, people's daily life is still influenced by them. A woman who travels alone may be morally chastised by traditional sexual morality and ideals of chastity. For young women, therefore, becoming a backpacker may incur a social stigma, which results in a stereotype of "sexual indiscretion".

There are still many negative opinions [about me], because my family is quite traditional. They think as a girl, you should not travel round by yourself, or you will fall into disrepute. My mother even doesn't dare to tell others about my travel experience... They are afraid that outsiders will regard me as a promiscuous girl. My parents always warn me not to break the pattern. (Yiyi, female, 24)

The effort required to cope with these constraints is also the process of producing meanings in relation to backpacker identity. These meanings associate becoming a backpacker with "independence" and "individuality". A backpacker is expected to be a contrarian, or to have an "alternative" character. In China, people are used to conforming with the expectations of society and family, and they are expected to do similar things and live similar lives to their peers. Becoming a backpacker in China is therefore to reject this sentiment. Chinese backpackers claim that they do not want to follow others blindly, and rather want to break free from external judgement and pressure. Becoming a backpacker thus provides opportunities for one to reflect on oneself and one's life, in turn prompting the person to be more willing to detach him or herself from everyday life conditions. For example, Yiyi stated that, "before I went out, I was a typical girl who was waiting to marry someone, cook for him, and bring up his children. But after I went away, I know my life can be different." Ultimately, by embarking on the backpacking journey and having interactions with other backpackers along the way, these individuals gradually 
integrate into the "backpacker" community. With this integration, they begin to form a more nuanced, or even blurred, image of what constitutes becoming a "backpacker".

\section{Phase II - (Re)inforcement of identity}

\section{Blurred image}

As Eliasoph and Lichterman (2003) argue, collective culture is continually (re)presented and (re)produced through social interactions among group members. Sharing similar views and values about life and the world, Chinese backpackers are found to be keen to interact with other backpackers. All the respondents have the experience of travelling in temporary company with other backpackers who they meet on the road or know from virtual backpacking communities. In comparison with surrounding people in daily life who make them feel alienated, backpackers claim that they feel "understood" and "accepted" by other backpackers. This leads to a sense of belonging to the group, and to a sense of collective identity. On the other hand, only through these in-group interactions, can backpackers represent their behaviour style, share their views and opinions, and integrate their self-image with the group identity. Such interaction is a good way, especially for new backpackers, to learn group norms, revise their previous image of the group, and further shape their backpacking practice.

In terms of the specific attributes of a "backpacker", it seems that Chinese backpackers reach an in-group agreement of what a "typical" backpacker is: He/she independently arranges his/her own flexible itineraries, is a low-budget traveller, travels for a long period, prefers getting off the beaten track, and regards hiking and hitchhiking as the ideal ways for moving around. However, through intensive interactions with other backpackers, they gradually realise that this ideal image becomes blurred.

The most contentious boundary of the group is the length of travel. In reference to Western backpackers, similarly, Riley (1988) chooses one year as her operational criterion, Sørensen (2003) thinks two-and-a-half-months is the socially defined boundary between backpackers and other travellers, and Loker-Murphy and Pearce (1995) define the threshold as four weeks. In the Chinese context, the average trip length is much less than their Western counterparts, with the average duration of 317 respondents' longest journey being 28.6 days. Furthermore, when considering the criteria of identifying as a backpacker, respondents had a substantial divergence of opinion regarding the time threshold. Importantly, half of the respondents think that length of travel has got nothing to do with the identity as a backpacker. Some respondents even claim that you cannot deny one's backpacker identity even if one only travels for three or four days, while others insist that there should be a criterion of travel duration for backpackers, which may range from one week to three months.

The budget is another contentious identity construct of the group. As discussed above, money is one of the biggest constraints for young Chinese backpackers. This results in their unique group culture of "qiongyou", a concept referring to low-budget travel. Besides its initial benefits of saving money, budget travel is seen as helping backpackers experience life beyond consumerism, and is considered to be the ideal way to travel. However, for some, qiongyou is not a necessary attribute, with many respondents stating that there is no link between backpacking and arduousness. Living in a comfortable hotel or having a sumptuous dinner is 
acceptable, and indeed many Chinese backpackers are likely to do so especially after undertaking physically challenging activities, such as cycle riding, hiking or mountain climbing. They call this "fubai", which is a playful irony and refers to debauchery in a literal sense (Lim, 2008). "If you trek a long journey, feel very tired, and finally stand at the front of an InterContinental Hotel, it's good to have some pleasure in it. It does not deny your identity as a backpacker." (Duan, female, 40).

Getting off the beaten track is another tenet of backpacking. However, Chinese backpackers also vary in their interpretations of "what is" and "what is not" the beaten track. A purist view is that backpacking is about exploring totally undeveloped areas, and refusing any tourist sites which require tickets. In this view, "hot" tourist sites are usually associated with mass tourism and over-commercialisation, both of which are to be avoided. On the other hand, more moderate views of backpacking do not exclude urban areas or tourist sites from their itineraries. Such backpackers believe that it is what you experience, not what you see, that makes you a backpacker. Therefore, they will not intentionally avoid the touristic attractions, they just do not focus only on them.

This blurred image results in difficulty in identifying group uniqueness. Therefore, during their backpacking practice, Chinese backpackers tend to continually compare themselves with other tourist groups, especially "mass tourists" and "Western backpackers". This is a strategy to help refine their group differentiation, improve their group esteem and to reinforce their social identity. In other words, an important part of becoming a backpacker is to develop an awareness and assertion of who they "are not".

\section{Social differentiation}

"Mass tourists" are the most important and most frequently mentioned outgroup for backpackers. Most backpackers reject being called mass tourists, and use the words "we" and "they" to distinguish themselves from mass tourists. They constantly compare themselves to mass tourists when outlining the image of backpackers, and form a series of opposite categories between "we" and "they". This is in line with Hogg \& Abram's (1988, p. 21) contention that members of a group will usually emphasise, or even exaggerate, the differences in specific dimensions between themselves and outgroup members, especially when the dimensions are of particular importance to them. Thus, it can be inferred that those categories which are emphasised by Chinese backpackers in order to differentiate themselves from "mass tourists" reflect the values of the group, and are an important aspect of "becoming a backpacker".

The biggest difference considered to exist between the two groups is the manner of travel. Backpackers name these two ways "tourism" and "travel" respectively, which can be seen as variants of the pair "tourists - travellers". Tourism is thought to be a superficial experience, and "tourists" are considered to be addicted to taking photographs. Backpackers contend that travel is not only visual, but also embodied, which is the reason that they look for physically challenging activities when backpacking. Besides "tourism vs. travel", backpackers also develop other pairs of opposite categories, such as "dependence vs. independence", "conformity vs. individuality", "uneducated vs. well-educated", "elderly vs. youth", "rich vs. poor", and "conservative vs. open", to differentiate themselves from mass tourists. For example, in the pairing "uneducated vs. well-educated", mass tourists are stereotyped as those who "litter and spit everywhere, talk loudly in the public, and don't join the queue" (Gufan, male, 23). Although admitting that there 
are some backpackers who do similar things, backpackers still claim that they are more environmentally-friendly and behave more responsibly than their "tourist" counterparts.

For Chinese backpackers, another special group is foreign backpackers, who can be seen as in-group or outgroup in different contexts. As backpacking is a relatively recent development for Chinese people, their initial image of backpackers is derived from Western backpackers. Thus, Western backpackers are treated as the "ideal model" for backpacking, and have become the primary source for Chinese backpackers to develop norms related to the group. Chinese backpackers imitate the practices of their Western counterparts and follow them to discover new backpacker destinations in China. However, it should be noted that, although they may encounter some Western backpackers during their journey, most Chinese backpackers have little experience of actual interaction with other nationalities, and so their perceptions and stereotypes of Western backpackers are mostly derived from indirect information, such as newspapers, movies and books. "Western backpackers" are therefore a somewhat constructed, and both fictional and functional, group for Chinese backpackers.

Most respondents view Western backpackers as having richer travel experiences than themselves, plus more travel-related skills and knowledges, while most Chinese backpackers are considered "amateurish" by comparison. The Western group are also bestowed with more "spiritual" qualities of backpackers. For example, they are considered to be more free-spirited, more open, and more adventurous. Meanwhile, Chinese backpackers think of themselves as being more conservative, lacking in independence, and preferring conformity. Interestingly, these terms are also used to describe mass tourists when Chinese backpackers are comparing themselves to mass tourists. This point can imply an identity "crisis", or at least an "anxiety", among Chinese backpackers, in their realisation that their differentiation may become eroded in relation to mass tourists. Thus, Chinese backpackers try to reinforce their in-group norms through the intergroup comparisons with Western counterparts, which can thus be seen as a further strategy to maintain their group differences from mass tourists.

\section{Phase III - (Re)construction of identity}

\section{Questioned image}

Once they have substantial experience and a deeper understanding of backpacking, many backpackers rethink and reflect on the group image. The non-conformist, or alternative, image of backpacking is frequently questioned at this stage. With the growing popularity of backpacking tourism in China, numbers of Chinese backpackers have increased dramatically in recent years. Many respondents expressed concern that this popularity, in a sense, represents conformity, which is opposite to the original spirit they have been encouraged by. They are critical of what they see as a growing number of backpackers who undertake travel "without a context", merely imitating others in form, especially the backpacker "stars", without really thinking about what they are seeking through their journeys. They consider some behavioural characteristics of backpacking, such as "getting off the beaten track" and "travelling on a budget", as reduced to mere symbols for showing off and exchanging status within the group.

Chinese backpackers are like a swarm of bees. I don't know why all the people rush to Tibet these years.... [They feel] lost, and don't know what to seek. So 
they may think that to go to Tibet is a good solution. After one or two months' journey to get there, they feel lost again, and don't know where to go next. The whole of China is lost now. (Jian, male, 21)

Indeed, some of those who consider themselves more experienced backpackers expressed a fairly strong sense of "identity crisis" within Chinese backpacking. They suggest that there are many "fake backpackers" or "fake donkeys", and that the word "backpacker" refers to too broad a group and has become overused. Uriely et al. (2002) find that Western backpackers consider the "fakers" are those who do not comply to the behavioural norms, such as length of trip, travel budget and visited destinations. However, Chinese backpackers' criteria to judge one's identity as a backpacker is quite different. "A real backpacker is one who has passion for travel. It doesn't matter how far he travels, or how much experience he has" (Zing, male, 23). Most respondents agree that spiritual qualities are more important for the identity as a backpacker. They describe a fake backpacker as one who is "fearful of everything" (Yiyi, female, 24), "gives up when facing difficulty" (Gufan, male, 23), or does not have a "tolerant attitude" (Hua, male, 20). These "fakers" are seen as not conforming to the group values, and simply using the label of "backpacker" as a tool to obtain a positive self-image. Many respondents worry that this will erode the meanings constructed by group members as the foundation of the collective identity.

You should have done this research in previous years. The word "backpacker" has been overused these years, and I am ashamed to admit that I am a backpacker. This word is spoiled.... They [fake backpackers] are under the banner of backpackers to profit at the expense of others... They are just mass tourists who take backpacks to pretend to be backpackers! (Liang, male, 45)

Consequently, there are some backpackers who detach themselves from the group after they complete their backpacking journeys. For them, backpacking experience is a process to demystify the romanticised image of backpacking. Having had opportunities to see the reality of backpacking, they come to realise the gaps between their original imagination of backpacking and the learned reality. Some feel disappointed about their journeys, which are not as exciting as previously expected. Some respondents even admit that, although they once held ideals about backpacking, after a long-term travel career, they have found that travelling is after all not an ideal way of life:

I think we need to return to normal life. Backpacking is also a form of life, but a deviant and special one. Life is not only for yourself. They [backpackers] may appear impressive, but suffer greatly when facing everyday life. There is no other way except return. We have to be driven to earn money and live. (Liang, male, 45)

Hence, different backpackers develop different understandings of and relationships to backpacking after their actual practice, and they either reject the identity in the end, or they continue working to (re)negotiate their backpacker identity. The most important strategy they employ to do this is narrating their backpacking experiences. 


\section{Narrated experience}

As Noy has argued in relation to backpackers: "Stories one tells of oneself are probably the best possible approximation to who one is" (Noy, 2004, p. 83), or who one intends to be. Narrative is therefore a strategy to continuously (re)construct one's backpacker identity, as narration can filter out the material which is not fit for, or may even be injurious to, identity construction. Simultaneously, certain types of narratives, implying particular spiritual qualities, are emphasized, and consequently (re)form the ideal image of backpackers which they intend to present to others. As one respondent put it, "I don't agree to grade backpackers according to material aspects, but I grade them from character aspects" (Hua, male, 20). An example is that the notion of freedom is emphasised by every respondent, and is clearly regarded as an important "spirit", or quality for Chinese backpackers. Some even claim that freedom is the only criterion for a backpacker. However, as mentioned above, as Chinese backpackers are usually labelled as "xiaoqingxin" (bourgeois), their narrative of freedom therefore is aesthetic rather than political.

In their narratives of backpacking practice, Chinese backpackers prefer to tell travel stories about that which happened on the road rather than in destinations, and they mainly focus on five types of activities: hiking, hitchhiking, cycling, climbing and camping, which all produce maximum differentiation from traditional, or mass, tourism. Similarly, to Western backpackers, "risk" and "suffering" are also two key themes featuring in Chinese backpackers' stories. The emphasis, and perhaps even exaggeration, regarding risk and suffering is not only a narrative strategy to show their strong will and courage, but also achieves reputation and status. Moreover, notions of risk and suffering also help backpackers construct non-ordinary experience, and bestow "meaning" on the journey, in that they are seen as a rebellion against the mundane as well as being thoroughly distinct from mass tourism.

However, the themes of backpackers' narratives change when stories focus on what occurred in destinations. These stories usually emphasise serendipitous opportunities to enter the "backstage" of local residents' lives. They may include having the opportunity to participate in their lives, and stories revolve around achieving some kind of "unexpected experience" which mass tourists cannot reach. In addition, backpackers do not only focus in their narratives on the experience itself, but also tend to show their social concern for the local communities, which is also considered a "good" quality of backpackers:

Then he lodged us in his own home.... The next day, we visited his daughter's school and had a talk with the head teacher. It's a very poor place. You can't mail things to their personal addresses directly, so we asked for the address of the school. Those children need clothes. After we return home, we will mail some clothes to them. (Wu, male, 24)

Such stories, with selected valued elements, repeated both directly by backpackers to each other, and via social and mass media, become important reassertions of backpacker identity. The narrated stories, frequently presented in the form of travel notes in online forums, influence various facets of backpackers' travel practice, including the arrangement of destinations, routes, scheduling, and accommodation. As a result, the activities in these travel notes are then repeated by other backpackers, thus continuously (re)constructing the group's behaviour and image. As one man said: "Maybe we browse the [virtual] forum too much, so everybody has a similar way of thinking, and then has similar thoughts" (Qin, male, 23). Whilst the process of becoming a 
backpacker thereby becomes reflective, and perhaps open to a certain amount of self-critique, it is clearly a process which is continuously being re-negotiated and re-worked.

\section{Discussion}

Following a grounded theory approach, the identity process of Chinese backpacker "becoming" has been developed, as outlined in Figure 1. Three main phases of Chinese backpacker becoming are identified, indicating that the process of becoming a backpacker in China is dynamic and contextual. The structure "image-identity-strategy" can be found in each phase, which suggests that backpackers' identities are products of interaction between socially constructed images and individual actions, or strategies.

[Insert Figure 1 about here]

The "becoming" process is not only the ongoing re-creation process of the image of Chinese backpackers, but also the process whereby backpackers actively negotiate their identities. For "non-backpackers" in China, the perceived image of backpackers is influenced heavily by mass and social media, through which the typical narrated stories of backpacking are widely circulated. In this way, a romanticised image, which represents the typical institutional orders of backpacking, is socially constructed. This romanticised image then encourages potential backpackers to make a separation from their normal life, which also involves producing new meanings in relation to backpacker identity. However, after one is intensively involved in backpacking, these meanings are again challenged.

Thus, in phase II, through interactions with other backpackers, the group image becomes blurred, and has to be re-negotiated. With the "massification" of "backpacking", the behavioural ideals of the group decline. Although Chinese backpackers hold a common view about the ideal image of backpackers, they contend that, these days, there are too many backpackers who have very few differences from other independent tourists. Thus, reluctantly or otherwise, they begin anew to take cognisance of what being a backpacker is. However, as group distinctiveness is important for group members to maintain their social identity (Hogg \& Abrams, 1988), under the circumstances of continuing massification, Chinese backpackers are driven to employ strategies to reduce the discrepancy between the ideal image and the blurred one, and then to reinforce their identities through a re-assertion of who they are and who they "are not". Social differentiation from mass tourists works as a negative reference to reinforce the group symbolic boundaries, while the comparison with Western backpackers works as a positive reference to reinforce the in-group norms.

In phase III, having more backpacking practice and experience, they develop more critical views about what makes them backpackers. Through bypassing the old behavioural norms and emphasising the more invisible and spiritual qualities, a new group image is reconstructed, endowing it with new group values. A backpacker identity thus has to be continuously reworked and re-asserted in order to continue to "be" a backpacker. This reconstruction and reassertion takes place particularly through presenting stories of backpacking, both in person and through social media posts, and also both during and after, or between, trips. The prosaic materials are filtered, while some carefully selected elements of backpacker identity are emphasised. 


\section{Conclusions}

This research set out to explore what it means to be(come) a backpacker in China. This exploration aimed particularly to address a gap in backpacker research, which tends largely to be non-region specific. The findings highlight the importance of backpacker research which deals with cultural specificities. Additionally, this article contributes by addressing a particular limitation in the extant research on Chinese tourists which is still largely premised on etic approaches and lacks in-depth understanding of "meaning-making" in relation to tourist being and becoming. The research has demonstrated not only that it is predominantly backpackers themselves who make the meanings of "backpacker" and "backpacking" what they are, but also that, in China, "backpacker" is a dynamic identity which is actively and continuously reconstructed. Highlighting the process and meanings of backpacker "becoming" in this way is especially pertinent in this backpacker context because, as Tomazos points out, an ontology "of becoming embraces flux, flow and continuity" (2016, p. 141). However, where Tomazos employed an "ontology of becoming" as a methodological premise to show how future backpackers' journeys are shaped by previous backpacking experiences, the present study has, via a grounded theory approach, produced a "theory of backpacker becoming" as an outcome. It proposes an analytical framework of "image-identity-strategy" to explain the identity construction of backpackers.

In relation to the Chinese context, backpacking is understood as introduced to China from the West, and contemporary Western backpackers are treated as models by their Chinese counterparts. Considered "amateurish" by comparison, some Chinese backpackers even identify with Western backpackers rather than their Chinese counterparts. In this context, backpacking in China lacks the historical tradition of a counterculture. Rather, it meets bourgeois tastes, and is endowed with images which make Chinese backpackers achieve a positive sense of status. As Chinese society is collective-oriented, people's identity construction largely depends on the relationship with others. The expectation of and impression on others thus becomes the key means to gaining a sense of status, where symbolic capital is highly valued. With the additional of Western consumerism, also, it has been argued that status seeking is on the rise among Chinese young urban adults (Podoshen, Li \& Zhang, 2011). Indeed, Cohen and Cohen (2015, p. 30) point out that China's "kinetic hierarchy" is still steep, with some forms of tourism still considered to be "the privilege, or a sign of distinction, and a demonstration of conspicuous consumption." This point appears to be emphasised by Chinese backpackers in that their backpacker identity renders them distinct even from other tourists so that they feel a heightened sense of status. Backpackers perceive themselves to be the elite among tourists, viewing backpackers as having richer experiences and more valuable qualities compared with other tourists. In this sense, while there are important contextual factors which are particular for Chinese backpacker identity construction, there are also interesting parallels with findings from general backpacker research (for example, Elsrud, 2001; O'Reilly, 2005). Indeed, the always fluid mix of regional contextual factors together with influences from other, broader ideas about "backpacking" inevitably renders a Chinese/Western cultural dichotomy problematic (see Tucker and Zhang, 2016). Nonetheless, it is the lack of historical tradition of such a "counterculture" in China, which makes the identity construction processes of Chinese backpackers worthy of attention. The structure "image-identity-strategy" thus provides a useful framework to understand the identification, meaning-making and "becoming" processes of Chinese backpackers. With the gradual institutionalisation of backpacking in China, a set of institutional 
orders for backpackers are formed, which results in particular images for the group. These images will become adopted by those who want to be called "backpackers", and then will influence and shape their behaviour. However, rather than passively accepting these images, backpackers actively negotiate them, employing various strategies in different contexts to continuously re-assert and/or reconfigure their backpacker identity. In this way, the group image keeps reforming, and in the Chinese context, "backpacker" identity is continually being transformed, reinforced and reconstructed, while the boundaries between these phases should be treated as blurred and overlapping. Therefore, the process of backpacker "becoming" is both contextual and dynamic.

Furthermore, this research has identified some of the unique issues Chinese backpackers face in relation to the pressures from what is often perceived to be "overwhelming" modernisation and urbanisation in China, along with the constraints from Chinese traditional values, as well as influences from Western society. However, whilst the present research has succeeded in furthering our understanding of Chinese backpackers' own meaning-making, a recognised limitation is that a tendency to generalise and present Chinese backpackers as a somewhat "homogenous group" still remains. For example, female Chinese backpackers are likely to represent a very different discourse from male backpackers, and this sort of nuance has not been fully elaborated in the above discussion. Therefore, further nuances within this tourist group remain to be fully understood. What is clear, though, is that since backpacking is a continuously expanding form of tourist practice in contemporary China, the ongoing inter-relationship between Chinese society itself and meaning-making through such "different" forms of tourism and tourist identity-construction, particularly when it is a somewhat "contrarian" identityconstruction, renders this particular field of enquiry a highly productive area of future research. 


\section{References}

Adkins, D. B., \& Grant, E. (2007). Backpackers as a community of strangers: The interaction order of an online backpacker notice board. Qualitative Sociology Review, 3, 1-22.

Ateljevic, I., \& Doorne, S. (2004). Theoretical encounters: A review of backpacker literature. In G. Richards \& J. Wilson (Eds.), The global nomad: Backpacker travel in theory and practice (pp. 60-76). Bristol, UK: Channel View Publications.

Charmaz, K. C. (2014). Constructing grounded theory: A practical guide through qualitative analysis (2nd ed.). Los Angeles, CA: Sage Publications.

Chen, G., Bao, J., \& Huang, S. (2014a). Developing a scale to measure backpackers' personal development. Journal of Travel Research, 53, 522-536.

Chen, G., Bao, J., \& Huang, S. (2014b). Segmenting chinese backpackers by travel motivations. International Journal of Tourism Research, 16, 355-367.

Chen, G., \& Huang, S. S. (2017). Toward a theory of backpacker personal development: Crosscultural validation of the BPD scale. Tourism Management, 59, 630-639.

Chen, H., \& Weiler, B. (2014). Chinese donkey friends in Tibet - Evidence from the cyberspace community. Journal of China Tourism Research, 10, 475-492.

Chen, Z. (2011). Backpackers: questionable rebels. China Book Review, 26-30.

Cohen, E. (1972). Toward a sociology of international tourism. Social Research, 39, 164-182.

Cohen, E. (1973). Nomads from affluence: Notes on the phenomenon of drifter-tourism.

International Journal of Comparative Sociology, 14, 89-103.

Cohen, E., \& Cohen, S. A. (2015). A mobilities approach to tourism from emerging world regions. Current Issues in Tourism, 18, 11-43.

Cohen, S. A. (2010). Personal identity (de)formation among lifestyle travellers: A double edged sword. Leisure Studies, 29, 289-301.

Cohen, S. A. (2011). Lifestyle travellers: Backpacking as a way of life. Annals of Tourism Research, 38, 1535-1555.

Currie, R. R., Campbell - Trant, T., \& Seaton, S. (2011). Joining the in - crowd: symbols for backpacker identity. International Journal of Culture, Tourism and Hospitality Research, 5, 4756.

Eliasoph, N., \& Lichterman, P. (2003). Culture in interaction. American Journal of Sociology, 108, 735-794.

Elsrud, T. (2001). Risk creation in traveling: backpacker adventure narration. Annals of Tourism Research, 28, 597-617.

Glaser, B. G. (2001). The Grounded Theory Perspective: Conceptualization Contrasted with Description. Mill Valley, CA: Sociology Press.

Glaser, B. G., \& Strauss, A. L. (1967). The discovery of grounded theory: Strategies for qualitative research. New York, NY: Aldine.

Hannam, K., \& Diekmann, A. (2010). From backpacking to flashpacking: Developments in backpacker tourism research. In K. Hannam \& A. Diekmann (Eds.), beyond backpacker tourism: Mobilities and experiences (pp. 1-7). Bristol, UK: Channel View Publications.

Hogg, M. A., \& Abrams, D. (1988). Social identifications: A social psychology of intergroup relations and group processes. London, UK: Routledge.

Hogg, M. A., Terry, D. J., \& White, K. M. (1995). A tale of two theories: A critical comparison of identity theory with social identity theory. Social psychology quarterly, 255-269. 
Larsen, S., Øgaard, T., \& Brun, W. (2011). Backpackers and mainstreamers: Realities and myths. Annals of Tourism Research, 38, 690-707.

Lim, F. K. G. (2008). 'Donkey friends' in China: The internet, civil society, and the emergence. In T. Winter, P. Teo \& T. C. Chang (Eds.), Asia on Tour: Exploring the Rise of Asian Tourism (pp. 291-301). London, UK: Routledge.

Loker-Murphy, L., \& Pearce, P. L. (1995). Young budget travelers: Backpackers in Australia. Annals of Tourism Research, 22, 819-843.

Long, Y. (2011). Backpacking tourism culture in network times: Taking Cang Qiong Outdoor Tourism Club as an example. Tourism Tribune, 26, 71-77.

Luo, X., Huang, S., \& Brown, G. (2015). Backpacking in China: A Netnographic analysis of donkey friends' travel behaviour. Journal of China Tourism Research, 11, 67-84.

Maoz, D. (2007). Backpackers' motivations the role of culture and nationality. Annals of tourism research, 34(1), 122-140.

Mead, G. H. (1934). Mind, self, and society: From the standpoint of a social behaviorist.

Chicago, IL: Univeristy of Chicago Press.

Miao, X., \& Bao, J. (2007). Grounded theory of non-standardized groups travel. Tourism

Tribune, 22, 48-54.

Muzaini, H. (2006). Backpacking southeast asia: Strategies of "looking local'. Annals of

Tourism Research, 33, 144-161.

Noy, C. (2004). This trip really changed me: Backpackers' narratives of self-change. Annals of

Tourism Research, 31, 78-102.

O'Regan, M. (2016). A backpacker habitus: the body and dress, embodiment and the self. Annals of Leisure Research, 1-18.

O'Reilly, C. C. (2005). Tourist or traveller? Narrating backpacker identity. In A. Jaworski \& A. Pritchard (Ed.), Discourse, communication and tourism (pp. 150-169). Bristol, UK: Channel View Publications.

Ong, C-. E., \& du Cros, H. (2012). The post-Mao gazes: Chinese backpackers in Macau. Annals of Tourism Research, 39, 735-754.

Paris, C. M. (2012). Flashpackers: An emerging sub-culture? Annals of Tourism Research, 39, 1094-1115.

Pearce, P. L. (1990). The backpacker phenomenon - preliminary answers to basic questions. In: Department of Tourism, Jams Cook University of North Queesland.

Podoshen, J. S., Li, L., \& Zhang, J. (2011). Materialism and conspicuous consumption in China: A cross-cultural examination. International Journal of Consumer Studies, 35(1), 17-25.

Riley, P. J. (1988). Road culture of international long-term budget travelers. Annals of Tourism Research, 15, 313-328.

Sørensen, A. (2003). Backpacker ethnography. Annals of Tourism Research, 30, 847-867.

Spreitzhofer, G. (1998). Backpacking tourism in South-East Asia. Annals of Tourism Research, 4, 981-985.

Stryker, S. (1980). Symbolic interactionism: A social structural version: Benjamin-Cummings Publishing Company.

Su, H., \& Ma, Y. (2009). On spatial travel flow pattern of intercontinental backpackers visiting China. Tourism Tribune, 24, 61-65.

Tajfel, H. (2010). Social identity and intergroup relations (Vol. 7). Cambridge, UK: Cambridge University Press. 
Tajfel, H., \& Turner, J. C. (1979). An integrative theory of intergroup conflict. The social psychology of intergroup relations, 33, 74.

Teo, P., \& Leong, S. (2006). A postcolonial analysis of backpacking. Annals of Tourism Research, 33, 109-131.

Tomazos, K. (2016). Backpacking Through an Ontology of Becoming: A Never - ending Cycle of Journeys. International Journal of Tourism Research, 18, 140-148.

Tucker, H. (2003). Living with tourism: Negotiating identities in a Turkish village. London, UK: Routledge.

Tucker, H. and Zhang, J. (2016). On Western-Centrism and "Chineseness" in Tourism Studies. Annals of Tourism Research, 61, 250-252.

Turner, J. C. (1975). Social comparison and social identity: Some prospects for intergroup behaviour. European journal of social psychology, 5, 1-34.

Uriely, N., Yonay, Y., \& Simchai, D. (2002). Backpaking experiences: A type and form analysis. Annals of Tourism Research, 29, 520-538.

Vogt, J. W. (1976). Wandering: Youth and travel behavior.pdf. Annals of Tourism Research, 4, 25-41.

Wang, Y., \& Jin, X. (2016). Review of Chinese outbound tourism research: Status quo and future directions. In X. Li (Ed.), Chinese Outbound Tourism 2.0 (pp. 39-53). Oakville: Apple Academic Press.

Welk, P. (2004). The beaten track anti-tourism as an element of backpacker identity construction. In G. Richards \& J. Wilson (Ed.), The global nomad: Backpacker travel in theory and practice (pp. 77-90). Bristol, UK: Channel View Publications.

Yu, Z. (2012). Research on backpackers' self-realization through tourist experiences. Dongbei University of Finance and Economics, Dalian, China.

Zhang, H., Wu, j., \& Li, M. (2007). International backpackers' motives, activities and satisfactions based on urban cultural tourism resources: A case study of Beijing. Tourism Tribune, 22, 23-29.

Zhou, X. (2008). Identity theory: An analyzing method of sociology and psychology. Journal of Social Sciences, 46-53.

Zhu, X. (2005). A probe into the Characteristics of backpackers and their influences on the development of Chinese tourist destinations. Tourism Science, 19, 38-43.

Zhu, X. (2009). Theoretical and empirical study on backpacker tourism. Beijing, China: China Tourism \& Travel Press.

Zhu, X., \& Lv, s. (2007). The backpackers: A review of some countries' countermeasures to develop backpacker tourism and the implications. Tourism Science, 21, 72-78.

Zou, Y., Lin, W., \& Zheng, X. (2014). A study on the formation mechanism of backpackers' tourism incidents: A qualitative analysis based on grounded theory paradigm. Tourism Science, $28,76-86$. 